\title{
PROGRAMME MANAGEMENT
}

\author{
KE Mokoka, FUNDISA;
}

A Mothiba, University of Limpopo

\begin{abstract}
This article outlines project management in the context of a nursing or other department having acquired external or internal funding for a specific project, which is part of the department and can be integrated into the department's broader activities. It then illustrates this process by using the University Nursing Education in South Africa (UNEDSA) project.

The UNEDSA programme is a funded initiative to transform nursing scholarship in South Africa with a focus on nurse academics and higher education. After a robust selection process, six university-based schools of nursing at the Universities of Fort Hare (UFH), Free State (UFS), Limpopo - Medunsa campus (UL), Pretoria (UP), Western Cape (UWC) and the Tshwane University of Technology (TUT) were selected and received grants of between $\mathrm{R} 14 \mathrm{~m}$ and R16 $\mathrm{m}$ to run projects which will support them in strengthening and transforming academic nursing in university-based nursing schools.

Project management is defined and then described in terms of the factors influencing it, risk management, monitoring and evaluation. The project management of the project in six universities is described in terms of its actions, such as site visits, technical assistance and capacity-building. The pitfalls and challenges are illustrated from the UNEDSA project and the lessons learnt are identified.

Although institutions of higher learning are not businesses and should focus primarily on their academic teaching, learning and research, they must be business-like in the way that they acquire and use their financial, physical and human resources. Acquiring project and programme management skills will ensure that they act in a business-like manner in the way that they manage donor funds.
\end{abstract}

Keywords: Project management; monitoring and evaluation; higher education; nursing education

\section{Introduction}

Higher education institutions in South Africa are on a major transformation trajectory to cope with the need to broaden access, manage knowledge strategically and operate in cost-effective ways to deal with the reduced resources available for the sector. In order for institutions to break out of this environment, where limited resources and restricted budgets impede delivery on their mission and strategic plans, there is a need to start looking for new external funding streams. To source external funding requires a department firstly to identify an area, idea, subject or activity within the school, department or community, which needs development or expansion and then approach various donors for funding. Institutions can also respond to published calls for proposals which are in line with their identified need. The structure of such funding tends to be project-based, which is 
competitive and requires a good project management skills'-set in order to enable departments to manage planning, implementation, monitoring and evaluation. It also requires a financial management capacity to manage external funding requirements specified by donors or funders in their grant agreements.

This chapter outlines project management in the context of a nursing or other department having acquired external or internal funding for a specific project which is part of the department, and can be integrated into the department's broader activities. It then illustrates this process by using the University Nursing Education in South Africa (UNEDSA) project.

\section{SECTION ONE: The theoretical basis of project management Defining project and programme management}

A project is a temporary endeavour comprising a series of activities aimed at creating a unique product through clearly delineated objectives within a specific time period and with a defined budget (Schwalbe \& Furlong 2013; Project Management Institute 2013).

A programme is a series of projects, the combined objectives of which contribute to a common, overall objective at institution, sector or country level (Schwalbe \& Furlong 2013; Project Management Institute 2013).

Two terms that are related to project and programme management are:

Stakeholders - individuals, groups or institutions that may influence, affect or be affected by the outcomes of the project (European Commission 1993)

Beneficiaries - Individuals or groups that benefit from the implementation of the project, be it in the short- or long- term (European Commission 1993).

In this chapter, the term "project(s)" will also be used to apply to the work at individual sites, and the term "programme" will be used for the national programme involving all the sites.

\section{Characteristics of a project}

Projects may differ in size or scope, but almost all have the following characteristics (European Commission 1999):

- A clear, definitive goal and objectives;

- A life-cycle involving a series of phases from beginning to end;

- A specific time-frame, stating a start and finish date;

- A dedicated budget and other resources which require managing, coordinating and tracking;

- Sequential activities that produce deliverables in terms of quality and quantity.

- The project may involve several departments and professionals.

- It may also entail doing something that has never been done before.

- Centralised responsibilities for management are specified.

- There are defined roles and relationships among project staff.

\section{Project life-cycle}

The project life-cycle entails the different phases through which the programme moves from start to finish. The following section briefly describes the four phases, as outlined by the Project Management Body of Knowledge (PMBOK ${ }^{\circledR}$ ): 


\section{Phase 1: Project initiation}

Project Initiation is the first phase in the Project Life Cycle and essentially involves starting up the project by defining its purpose and scope. In cases where the project is already identified, the proposal has been submitted and funding has been secured. This step entails actual preparations for implementation. Key steps may include appointing a project team and setting up a project office.

\section{Phase 2: Project planning}

This involves creating a number of planning documents to help guide the team through project delivery. The various plans include project, resource, financial, quality, risk, communication and procurement plans. Suppliers are contracted and other documents such as policies and guidelines are also drawn.

\section{Phase 3: Project execution}

This is the longest phase of the project, where implementation takes place, and management processes are undertaken to monitor and control the project outcomes and deliverables. Processes include managing activities, timelines, budgets, cost, quality, change, risk issues, suppliers, customers and communication strategies. Where a project is managed remotely or as part of a bigger programme, it is critical that implementing institutions are supported. This support can be in the form of an appointed programme management team and entails regular visits, seminars, webinars, workshops and conferences. The importance of these platforms is to gain support from other project implementers, experts on the areas of projects being implemented, funders and to strengthen communication as the team moves towards achievement of the project goal.

\section{Phase 4: Project closure}

This final phase entails the completion of all project activities across every phase of the project. Project closure involves releasing the final deliverables, handing over project documentation to the institution or funder, terminating supplier contracts, releasing project resources and communicating the closure of the project to all stakeholders. The last remaining step is to undertake a post implementation review to quantify the level of project success and identify any lessons learnt by the customer. Depending on donor requirements, an external evaluation can be conducted to strengthen the validity of everything that was achieved and reported on by the project.

It sometimes becomes inevitable that a project cannot complete its activities within the timeline agreed and contracted with the funder. If this happens, an extension can then be applied for: however, strong motivation is required. Funders might have certain pre- conditions for granting an extension, such as available funds, narrowing the project focus or they might even decline the request for an extension. Constant monitoring, risk identification, teamwork and support can all help in a project being completed within the agreed time.

The phases above are described according to $\mathrm{PMBOK}^{\circledR}$. Various funding organisations may establish different phases or incorporate various steps in a phase. A case in point is the European Union (EU), currently one of the major funders of programmes in South Africa. The EU identifies 6 steps: programming, identification, appraisal, financing, implementation and evaluation as those that are likely to achieve optimum project impact in line with its objectives.

The United Nation's Socio-Economic and Gender Analysis Programme identifies six stages: identification, proposal preparation, appraisal, approval and financing, implementation and Monitoring and, finally, evaluation. 
Despite the difference in scale and nature of projects, there are aspects of sound project management that are universal in nature. Of cardinal importance is that the project cycle is a continuous process in which each stage provides the foundation for the next, as well as offering value for money and a definite completion target.

\section{Factors to be considered}

There are four primary elements that need to be considered in a project:

Scope - This mainly refers to the size of the project in terms of the work that needs to be done and the products, results or services that need to be delivered.

Time - the period during which the project is scheduled to run;

Cost - Resources needed to complete the project;

Quality - The state of the services or products achieved at the end of the project.

These four elements are interrelated and are usually specified in the agreement letters or project contracts.

\section{The project management system}

Managing a project includes monitoring or tracking the progress that a project is making from the time it is designed through to implementation. This requires a system for monitoring the entire project cycle. There are certain critical elements or activities in a project that need to be in place if a project in to be successfully managed and monitored:

\section{Programme goal and objectives}

The overall goal of a programme with several projects gives direction to each individual project which will then formulate its own goal based on the overall programme objective. The project goal is a concise statement of the purpose of the project. Objectives stem from the goal and specify what the project is going to do. It is therefore important to have clear project objectives. The more specific the project objectives, the greater the chances are of achieving them .The acronym "SMART" is used to describe a good objective (The Global Fund 2009):

Specific - Clearly defined, leaving no room for ambiguity or misinterpretation;

Measurable - It must be clearly stated in the objective what will be done and how it will be measured to determine if the project goal has been met. Setting a measurable objective makes project evaluation easier.

Achievable - Be realistic about what the programme can achieve in terms of the scale/scope of the project, the time that the project is set to run, human and other resources available and the allocated budget.

Relevant - Objectives are the building blocks or steps towards meeting the project and programme goals. They therefore need to relate and be relevant to the goals.

Time bound - Be clear in the objectives about the time-frame in which the programme/activities will take place. 
Project teams should spend time on developing good objectives as they "make or break" a project. If team members are involved in the development of project objectives, they take ownership of the project, creating a greater chance towards project success.

\section{The Logical Framework}

When donor agencies such as the United States Agency for International Development (USAID) started to award huge grants to developing countries for different projects and programmes, certain problems which affected the success of such projects were identified. These included poor, vaguely structured plans, a limited understanding of what the project was set to achieve, unclear objectives as to what the project staff should be responsible for, and what should be measured in order to declare a project successful. This led to the development of the Logical Framework as a tool to remedy these problems (Broughton \& Hampshire 1997, AusAID 2002).

The logical framework or LogFrame can be defined as a tool or process that informs funders, the project team and stakeholders about the state of the project, as well as how the project is performing given the actual resources and guides in the planning of the intervention when the project performance needs to be improved. It can be used in various phases of the project life cycle to analyse the project concept, design projects, measure performance, plan, manage and evaluate the project. The logical framework focuses on clarity and detail and is closely linked to the budget. It indicates how and why a project will work. Different variations of the logical frameworks are used, depending on different agencies, most importantly, the funder. However, the approach has the same background and, if understood and used correctly, yields the same results. Different authors refer to different terms, including The Logic Model. LogFrame, Logical Framework or Logic Framework Approach (LFA).

These specify what the project is intended to achieve (objectives), what resources are required to meet objectives (inputs), what will be done with the resources (activities), what tangible products will result from the actions (outputs), what changes will occur as a result of these products (outcomes), what the long-term effects of the achieved results (impact) are, and how this achievement will be measured (indicators).

Using the LFA fulfils several functions during the project cycle. It directs the development of structured ideas by clarifying objectives; it provides a logical methodology which directs the focus of the project towards achieving the set goals, assists in building a close link between the project elements and the project objectives, helps to identify possible risks and pitfalls during project implementation and provides a framework against which project progress will be monitored and evaluated. The methodology can be applied to a variety of projects.

Project work plan

A work plan outlines all the processes by which a project can operate so as to accomplish set goals and objectives. A work plan enables the project team to break down the project into small, manageable, achievable tasks, and guides the team in specifying activities that need to be performed. It also identifies responsible people and helps in monitoring the project progress.

Work plans can be as comprehensive as the project team would like them to be. A generic work plan specifies the title of the project, goals and objectives, activities under each objective, timelines and responsible people for each activity in the plan. Resources or costs attached to each activity or objective can also be specified. 


\section{Monitoring and Evaluation ( $M$ \& E)}

Monitoring involves the collection of routine data that measures progress towards achieving programme or project objectives. It is used to track changes in performance over time and permits stakeholders and funders to make informed decisions regarding the effectiveness of programmes and the efficient use of resources (Broughton \& Hampshire 1997; The Global Fund 2009). Monitoring is sometimes referred to as process evaluation because it focuses on the implementation process and asks key questions:

- How well has the programme been implemented?

- How much does implementation vary from what was initially proposed?

- Did the programme benefit the intended people? At what cost?

As an on-going, continuous process, monitoring requires the collection of data at multiple points throughout the project cycle from the beginning, in order to provide a baseline for assessment and to determine if activities need adjustment during the intervention so as to improve desired outcomes.

Evaluation measures how well the programme activities have met expected objectives and/or the extent to which changes in outcomes can be attributed to the programme or intervention.

\section{Why is $M$ \& E important?}

Monitoring and Evaluation helps implementers to make informed decisions regarding programme operations and service delivery, based on objective evidence, to ensure the most effective and efficient use of resources, objectively assess the extent to which the programme is having or has had the desired impact, identify areas where it is effective and where corrections need to be considered. Organisational reporting and other requirements are met, which convinces donors either that their investments have been worthwhile, or that alternative approaches should be considered.

\section{The M \& E Plan}

Every project or intervention should have a monitoring and evaluation (M\&E) plan. This is the fundamental document that details a programme's objectives and describes the procedures that will be implemented to meet set objectives. The plan shows how the expected results of a programme relate to its goals and objectives, describes the data needed and how this data will be collected and analysed, how this information will be used, and how results will be disseminated to all stakeholders.

Using frameworks is one way to develop a clearer understanding of monitoring and evaluation. The Logical Framework is one such framework used for projects.

Indicators

An indicator is a measurement value which changes from the baseline level at the time the programme starts to a new value after the programme and its activities have yielded outcomes or have made their impact felt. Indicators can either be quantitative or qualitative. Quantitative indicators are numeric and are presented as numbers or percentages. Qualitative indicators are descriptive observations and can be used to supplement the numbers and percentages provided by quantitative indicators. A good indicator is non-directional and can vary in any direction (The Global Fund 2009; EU 1999). 
Some general guidelines for the selection of indicators are:

- Select indicators requiring data that can realistically be collected with the resources available.

- Select at least one or two indicators (ideally, from different data sources) per key activity or result.

- $\quad$ Select at least one indicator for each core activity (e.g., training event, social marketing message, etc.).

- $\quad$ Select no more than 8-10 indicators per area of significant programme focus.

- Use a mix of data collection sources whenever possible.

\section{Project Risk Management}

A risk is defined as any occurrence or event that may happen during the life-cycle of the project, or even in the future, that will most likely affect the programme or project schedule, budget or scope adversely. Risks may be anticipated, but with correct and timely planning, can be avoided, minimised and resolved without causing any negative impact to the programme or project. In short, risk is the possibility that an undesirable event will occur, which could result in some loss. Risks can occur anywhere along the project life-cycle, affecting the scope, time-lines, resources or deliverables of the project. Risk management involves the assessment, identification and response to the risk, in order to resolve or minimise the likelihood and impact of its occurrence on the achievement of project goals.

\section{SECTION TWO: Case study of Programme Management: Management of the UNEDSA Programme Introduction}

The UNEDSA programme is a funded initiative to transform nursing scholarship in South Africa, with a focus on nurse academics and higher education. Two donor organisations, Atlantic Philanthropies and ELMA Foundation made a generous grant of just over R100 million over a four-year period from 2009, to fund projects aimed at transforming nursing in South Africa. After a vigorous selection process, six university-based schools of nursing at the Universities of Fort Hare (UFH), Free State (UFS), Limpopo-Medunsa campus (UL), Pretoria (UP), Western Cape (UWC) and the Tshwane University of Technology (TUT) were selected and received grants of between R14m and R16 m to run projects which will support them in strengthening and transforming academic nursing in university-based nursing schools. The universities of Pretoria and Limpopo collaborated and did their project together, duplicating activities at both institutions. The UNEDSA programme has changed programme managers twice in its lifetime, and is currently managed by the Forum of Nursing Deans of South Africa (FUNDISA). FUNDISA took over about half-way through the programme and is working towards closure, with activities ending in December 2013.

The overall goals of the UNEDSA projects were to:

- $\quad$ Facilitate the transformation of nursing scholarship at grantee university-based nursing schools/departments so that research, clinical practice and nursing education are strengthened and sustained;

- Improve the quality of nursing education and research;

- Boost the status of nursing professionals;

- $\quad$ Advance nursing practice;

- Improve the quality of nursing clinical practice. 
While the projects differed in terms of their objectives, activities and deliverables, there were some cross-cutting elements that were common to most, if not all projects, all aimed at transforming nursing education, clinical practice and research.These cross-cutting elements included capacity building under academic staff and students, strengthening research and nursing scholarship, developing new models of nursing education and clinical practice, improving community engagement and collaborating with nurse academics nationally and internationally.

\section{The projects}

Each of the institutions embarked on a project that responded to the overall aim of the UNEDSA programme. A brief discussion of the project objectives and key deliverables follows:

\section{Tshwane University of Technology}

The goal with this project was to develop and implement a primary healthcare service that was community-based and created learning opportunities for clinical practice through the placement of nursing students. The project deliverables were a mobile PHC Community- Based Health Service rendering mother and well- baby, childhood development (including early childhood intervention and school health), lifestyle diseases, cancer screening and palliative care, community health practice learning opportunities for basic and post- basic students, increased nursing research output and capacity-building within the school of nursing.

\section{University of Fort Hare}

The goal of the project was to support the Department of Nursing Science in transforming nursing scholarship in the Eastern Cape Province so as to deliver adequately equipped physical environments that enabled teaching and learning through spaces, furniture and equipment conducive to preparing undergraduate and postgraduate learners. Further objectives were to improve teaching and learning capacity in the DNS by increasing the numbers, qualifications and scholarly skills of new and existing faculty members to Master's and PhD levels, as well as developing and implementing two new postgraduate degrees; namely, a research Master's programme and a PhD programme, and establishing a research programme for the school.

\section{Univeristy of the Free State}

The UFS had three objectives for their project, which were to transform environments, people, and programmes, establish a teaching and learning facility with state-of-the-art equipment and establish a centre for continuous professional development.

Deliverables were an increased scholarship development in terms of publications and presentations at national and international conferences, a greater number of research outputs, a Virtual Health and Teaching and Learning Facility with state-of-the-art equipment and facilities for training, leadership in simulation-based teaching and learning, and a unit for continuous professional development and research capacity development that will serve both practising nurses in public and private healthcare facilities and staff of the School of Nursing.

\section{University of the Western Cape}

The overall purpose was to enhance the quality of nursing scholarship and practice in the Western Cape through the establishment of a Centre for Teaching and Learning Scholarship. The Centre's deliverables included a programme on clinical preceptorship training, increased postgraduate output 
of students in Master's and Doctoral programmes, and increased research and scholarship outputs by academics in terms of publications in peer-reviewed journals and research projects.

\section{University of Pretoria/University of Limpopo}

Objectives of the collaborative project were to implement a community-oriented nursing education model in undergraduate and postgraduate teaching and learning; enhance the knowledge, skills and attitudes of practice nurses, leading to practice improvement in community-oriented women and child healthcare; establish communities of practice; increase research scholarship output, as well as to found two learning centres in Tshwane and Jubilee District Hospitals.

Expected deliverables were the incorporation of the model in the nursing curriculum and development of new study guides for nursing education; an increased number of trained practice nurses in various topics related to community-oriented women and child healthcare; evidence of practice improvement; an increase in the number of nurses completing or still busy with Master's and Doctoral studies; a marked increase in the number of publications and research outputs and two fully functional learning centres at the district hospitals attached to the two universities.

\section{The project management process and activities}

FUNDISA took over the programme management of UNEDSA midway, after the projects had been running for nearly two years, with different projects at different levels of project execution. The starting point had to be assessment of the progress made by each project in order further to plan the management process. To achieve this, a baseline evaluation was conducted. This took the form of a strategic evaluation by an external consultant accompanied by the FUNDISA Chief Executive Officer (CEO), with the aim of providing a short overview of each project and identifying areas that required technical support and assistance, as well as making recommendations for actions to be taken by the projects and the programme management.

The visit was followed by a preliminary plan of interventions by programme management which would be implemented at different intervals. These included site visits to each project at set intervals and as necessary and also capacity-building activities such as workshops, meetings and conferences. These addressed themes that would enhance project performance; for example, building a research programme in a nursing school, as well as offering sustainability and technical support in areas such as research, financial management, monitoring and evaluation through the engagement of consultants.

\section{Site visits}

The aim with the site visits was to assess project progress, communicate with project staff to hear if the project was experiencing any challenges in executing some of its activities, and to observe the general situation in order to gain a broad overview of the projects. The focus was on establishing whether or not project staff were managing their budgets in line with set objectives, supporting projects by developing and implementing work, monitoring and evaluation plans, and visiting sites or spaces that were developed as part of the project. Interaction with project staff and beneficiaries, hearing their stories and experiences, as well as giving guidance regarding the project where required, was also assessed. Another highlight during the visits was interacting with the institution's executive management and staff in other departments such as supply chain and finance. These visits 
provided a communication platform which was important in building relationships between the institution, school and programme management. Project staff acquired a sense of belonging and an opportunity to voice concerns, ask questions, and obtain clarity on matters that might affect their performance. Meetings with the institutions' executive, namely the Dean, Vice-chancellor, Head of Finance and others, were critical in building and maintaining relationships. This was also an opportunity to discuss issues that could affect the successful completion of the project and also, at times, to act as intermediaries in issues which the project might find difficult to bring up with the executive; for example, procurement, services, maintenance, policies and staff-related issues. The relationship also demonstrated that the project was recognised as part of the institution or nursing department and stood a better chance of sustainability or being absorbed into the school and institution. Beyond the site activities, the visit was a communication vehicle between the project and the funder.

\section{Capacity building}

Based on site reports, what was evident during visits was that there was a need to support projects relating to various areas of project management work in the departments. It became imperative that opportunities needed to be created to build capacity and improve the knowledge and performance of project staff. Capacity building was in the form of workshops on various themes related to the project. Sharing knowledge and exchanging experiences during these workshops was aimed at strengthening project staff so that they could better plan, manage and implement activities to assist them in achieving project objectives. Capacity building workshops were held annually, where an expert was invited to present a discussion on a topic of interest. Examples of subjects handled at these workshops were building a research programme in a nursing school, project sustainability, financial management and project close-out. Another platform was created through seminars or conferences, where each grantee-nurse would present their particular project. This was a valuable experience, as participants could learn from one another and share working formulas and strategies which could make their projects work. Policies and guidelines were also important in building the capacity of project staff.

\section{Technical support}

As in the majority of funded projects, the UNEDSA schemes received funding to perform certain activities that would yield certain outcomes or results. It was therefore vital that project management should follow the results-based project management approach. This approach focuses on project results or outcomes, founded on the set objectives. For this approach to be successful a number of tools are required to guide projects in working towards achieving results. In the case of UNEDSA projects, such tools included, but were not limited to, policies, guidelines, a logical framework, work plans or Gantt charts and monitoring and evaluation templates. In some of the projects, the staff developed a number of checklists which helped them to track activities and assess the feasibility of certain activities and the level at which project activities were implemented. Tools such as the work plan also helped to enhance accountability, as responsibilities were delegated to specific persons or groups. In the absence of tools such as a monitoring and evaluation plan, the project could face delays in project execution and possibly completion, as there would be no way to assess if activities were on track or not. 
One of the major interventions of the FUNDISA team was to create financial policies for the programme and to assist institutions in implementing these. It had been an oversight in the initial phases that such policies were not created and each institution was left to cope with the massive financial responsibilities without clear guidelines. What made it worse was that for a number of the institutions this was the largest external funding they had ever received, and they had no internal policies to deal with such funding. Some of the projects involved community-based activities for which the institutions had no previous experience and policies. Another problem involved changes of project managers, which inevitably gave rise to different interpretations and emphases, thus creating further difficulties. For instance, the second project manager had a "spend all as fast as possible" philosophy, while FUNDISA preferred slower, more accountable and goal-directed spending. FUNDISA sent a financial expert on a site visit to each location and, based on these visits, he created financial policies.

Technical support also included assistance with report writing and revision, and help with internal problems such as staffing issues. This was dealt with in small group meetings between the project manager and appropriate staff from the site, as well as extensive use of telephone and e-mail consultation.

\section{Project Monitoring and Evaluation}

The Logical Framework was identified early in the programme as the major tool to manage the UNEDSA programme from planning and design to evaluation. It is regarded as a causally linked sequence of events, starting with the project goal and objectives, resources (inputs) needed to perform certain actions (activities), products of those activities (outputs), results of what the products will bring (outcomes), leading to the ultimate fulfilment of the project goal (impact). This framework is commonly used in development projects to track project activities or progress and to assess whether or not the results of these activities are meeting the set goals and targets (The Global Fund 2009).

For the UNEDSA project, monitoring and evaluation occurred on two levels. At programme level, a plan was developed earlier in the project life cycle, to track and assess the entire programme as a unit. At project level, each project also developed its own plan which led towards the overall UNEDSA programme $M \& E$ plan. To make the process manageable, overall programme outcomes were to be evaluated. It was also important to identify indicators at two levels - those specific to each individual project and those that cut across all projects. Care was taken not to develop "indicator overload", characterized by having a large number of indicators that were almost impossible to measure. While other projects, depending on their overall purpose and goal, were starting to show an early impact, the focus was on the short- and-mid-term outcomes of the projects.

\section{Project close-out}

The purpose of project close-out is to assess the evidence of completion, learn the lessons generated throughout the project life-cycle and identify best practices that could be applied to future projects. This is the last phase of the programme and entails the formal finalization of a project, both operationally and financially. There is usually an overlap between closing operations and the cessation of funding, with operations and activities being closed first and then all financial 
obligations. Due to delays and certain unforeseen circumstances, most of the UNEDSA projects requested a no-cost extension beyond the agreed close-out date so as to be able to complete their activities. This was granted and all the project operations will be closing at the end of the year (in December 2013). Some of the final activities, such as financial close-out, the closing of supplier accounts, transfer of assets to the institution and termination of other contracts will continue into the first quarter of 2014.

Among other activities, project closure includes the confirmation that the terms and conditions of the project have been met and objectives achieved. Furthermore, deliverables should be evident, all evaluations including the final external one need to have been conducted, project resources transferred or discussed, and records archived or stored. Another important final activity, where funds and funders allow, involves project celebrations, where outstanding project work is recognised.

\section{Pitfalls and challenges}

Like any task, a project can have pitfalls. It remains the responsibility of the project leader or manager to identify and manage any challenges that might threaten the successful execution of the project. This can be done through teamwork and on-going communication between different team members.

Some of the pitfalls of project management (PMBOK 2013) and their application to the UNEDSA programme management are as follows:

- Poor communication, which may result in unclear roles, responsibilities and expectations due to information gaps. Project staff are considered to be part of a team which should work towards a common goal and, subsequently, towards successful project closure. Communication with funders is also critical. It fosters soun relationships and feelings of trust. Even when things are not going according to plan, it is easier to express concerns and agree or negotiate on changes such as extensions or deadlines. Open communication creates a platform where discussions can be held regarding different team members' roles, responsibilities, channels and lines of reporting. It strengthens accountability and also contributes towards building the confidence and morale of project team members.

UNEDSA: Within the projects, communication was never a big issue as project staff had previously worked together and seemingly got along. Meetings and structures such as governing bodies also ensured that communication channels remained open. Since project teams were a new entity in most nursing schools, the schools often did not have job descriptions and performance management systems for these staff members.

- Lack of a clear definition of the scope of the project, which may lead to misunderstanding what is required or committed to in the project contract. Changes and continuous growth, either within the programme vision or outside it, cannot occur if a project is not clearly-defined, documented or controlled. This can lead to unnecessary activities and expansion of the project beyond its scope, time and budget, a phenomenon called scope-creep. The result is a project that has grown so big that it has become unmanageable and unattainable, or has changed focus totally.

UNEDSA: This was one of the pitfalls that some of the projects could have faced. It became necessary to review some of the project objectives which could easily have led to scope creep. 
The lack of clear policies from the start, especially financial policies, also made things difficult. However, even if they were developed rather late, such policies did much to clarify responsibilities of the fund recipients. Similarly, having a clear and well-defined work plan with specific timelines and schedules can help to contain project costs in the long run.

Some schools followed unwritten project plans, which sometimes did not coincide with the written plan submitted in their proposals and approved for the project. This became evident during evaluations, when reviewers would be told "That is not what we meant..." or "We planned to..." when they followed the written project proposals in evaluation. Such agendas, while very clear in the minds of project staff, but totally obscure to external persons, should be identified during site visits and incorporated into the written documents.

- Lack of "buy-in" from senior management is another major pitfall in project management. Support from the institutions' senior executive management is of cardinal importance in strengthening project success. It also builds confidence between funders and can even be used as leverage for failure funding.

UNEDSA: This was not a problem during the UNEDSA project; however, successful achievements within some of the projects led to top management involving the nurse-leaders more extensively in other university activities and projects, diverting their time and attention during crucial project phases. This needs to be handled with care, since leadership development in nursing is a desired outcome which should not be jeopardized, even while the success of the project is ensured.

Implementation of new project management guidelines should be accomplished by consultation and training so as to ensure enforcement, application and implementation of these guidelines.

- Lack of a project methodology or framework can lead to project failure. It is also critical to choose a methodology that will enable the handling of the entire project cycle. An example of such a methodology would be the Logical Framework or LogFrame. Such a methodology will enable the project team to monitor whether or not the project is on track and assist them in identifying problems which could hamper achievement of progress milestones.

UNEDSA: In the UNEDSA programme, the implementation of the Logical Framework was problematic and the project teams spent endless hours trying to perfect the documents. When FUNDISA took over, the evaluation documents had either not been finalized, or were not being used strategically on any of the sites. The central programme manager therefore spent face-toface time finalizing these documents by simplifying them and making sure they were used in the annual reporting.

The need for standardised formats of reporting to ensure that project information is clear and unaffected by different methods of reporting became clear during the process. Since most nursing academics are not skilled project managers, they often needed capacity building in terms of the use of the logical framework and tools such as checklists, workplans and Gantt charts to help them to keep on track with project activities.

- Continuity and consistency in terms of resources.

UNEDSA: The biggest challenge faced by the projects and the programme management was project staff turnover, which seemed to be common to all projects, as well as to the programme management staff. This led to delays in implementation which, in a project with set timelines, could lead to a failure to adhere to these timelines. It could also pose challenges such as a lack of clear understanding of the process, policies and plans amongst ever-changing staff members. 
There is little one can do about this, but keeping a no-cost extension in mind might assist in dealing with delays.

\section{Lessons learnt}

Among the pitfalls and challenges which were experienced in some of the UNEDSA projects, there were tremendous successes and some valuable lessons which could help to shape future projects.

- The teams' interactions need to be managed properly with clear communication of roles and responsibilities to each member of the project staff. This is enhanced by job descriptions.

- Financial planning according to these objectives is also essential. Spending time on project planning will enable the team to understand what the project needs to deliver and to avoid additional work or risks that were not envisaged as a result of hurried planning. Proper planning should include risk and quality management planning.

- Expected quality standards should form part of project planning and be applied throughout the project life-cycle so that the project is completed successfully in terms of quality and quantity. Sometimes project managers became fixated on numbers while losing sight of quality, something the funder was clearly interested in.

- Having an M\&E specialist or consultant from the beginning of the project would have been of great assistance in rewriting and reviewing the project plan as necessary, making it relevant, feasible and attainable, as well as identifying new emerging needs and risks. The objectives for such large projects are dynamic and should be adjusted strategically and sensitively so as to retain the grant conditions in a changing world.

- Monitoring and evaluation should also be included in the project financial plan and be budgeted for throughout the project life-cycle.

- There needs to be a process in place for tracking any changes in project scope and forecasting any additional costs that might arise from such changes.

\section{Conclusion}

With renewed interest in projects as a way of improving healthcare services, it is necessary to start looking for funding beyond the institution. This is the case with the UNEDSA programme, where there is a need to sustain some of the elements of these projects beyond the funding cycle. Although institutions of higher learning are not businesses and should focus particularly and primarily on their academic teaching, learning and research, they must be business-like in the way that they acquire and use their financial, physical and human resources. Acquiring project and programme management skills will ensure that they act in a business-like way in terms of how they manage donor funds. It will help maintain sustainability and continue to secure more external funding as good practices and sound management of activities and financial resources are demonstrated, as well as delivering project outcomes within budget and on schedule. Where project-based funding is received, accountability for delivery matched with expenditure is critical for future funding. This requires training nurses who are able to take up leadership roles in transforming healthcare practice, something which is critical to improving health outcomes, and which can be achieved through teaching and learning which focuses on leadership development. A common problem identified in various organisations and institutions is a lack of resources. Identifying problems in the healthcare setting and following the principles of project management will contribute to maximising limited resources and ensuring quality health outcomes. Principles of project management in healthcare; 
namely, identifying the problem or need, planning an intervention, implementing or executing the plan, as well as monitoring, controlling and evaluation, are closely related to both the nursing and management processes. While the latter two are operational in terms of their on-going nature, project management has a beginning and an end which, in healthcare, can be very beneficial in terms of seeing interventions or actions implemented on time, within budget, as well as monitored and completed with tangible results, outcomes or milestones.

\section{References}

Australian Agency for International Development. 2002. The Logical Framework Approach. www.ausaid.gov.au/ausguide/ausguidelines/1.html. Accessed 24/04/2013.

Ben-Dak, J.D. 1999. The Logical Framework in a Project Management System. Handbook for Systems Engineering and Management. New York: John Wiley \& Sons.

Broughton, B. and Hampshire, J. 1997. Bridging the Gap: A Guide to Monitoring and Evaluating Development Projects. Canberra: Australian Council for Overseas Aid.

European Commission. 1993. Project Cycle Management: Integrated Approach and Logical Framework. http://publications.europa.eu/tools/index en.htm. Accessed 20/05/2013

European Commission. 1999. Project Cycle Management Training Handbook. http://publications.europa.eu/tools/index en.htm. Accessed 20/05/2013

Jones, S. 2011. UNEDSA Strategic Learning Site Visits (unpublished report)

Kerzner, H.R. 2013. Project Management: A Systems Approach to Planning, Scheduling and Controlling. New York: John Wiley \& Sons.

Project Management Institute. 2013. A Guide to Project Management Body of Knowledge (PMBOK ${ }^{\circledR}$ Guide). $5^{\text {th }}$ Edition. Pennsylvania: Project Management Institute Inc.

Schwalbe, K. and Furlong, D. 2013. Healthcare Project Management. Minnesota: Schwalbe Publishing.

The Global Fund. 2009. Monitoring and Evaluation Toolkit. $3^{\mathrm{RD}}$ Edition. http://www.theglobalfund.org. Accessed 29/08/2012. 